\title{
Electrochemistry of Eugenol and its Metabolism on a Bare Screen-Printed Electrode
}

\author{
By Rafaela Vasiliadou*
}

\begin{abstract}
Eugenol is an essential oil widely used in pharmaceutical and food industry. However, the metabolism of eugenol leads to the formation of a highly reactive phenoxyl radical that can induce toxicity with macromolecules. Herein, a simple and a costeffective methodology was described for the mimicry of engenol metabolism. Electrochemical measurements were recorded on bare screen-printed electrodes (SPES) and the generated metabolites were collected and detected by electrospray ionization (ESI)/Mass spectrometry (MS). The reactive intermediate was successfully formed illustrating a cheaper alternative towards the mimicry of human metabolism.
\end{abstract}

Keywords: Electrochemistry, Metabolism, Screen-Printed Electrodes.

\section{Introduction}

Drug metabolism is an important part of drug development since reactive metabolites are detected and potent drug candidates are excluded from further studies (Plumb et al., 2003; Andrade et al., 2016). In vitro and in vivo studies that are currently used for the mimicry of human metabolism are tedious and expensive (Lohmann et al., 2010; Laffon et al., 2017). As a consequence, the need for cheaper and faster alternatives is essential. Considering that the majority of phase I reactions are mainly oxidations (Chadwick and Shaw, 2002; Gul et al., 2017); electrochemistry can provide a suitable method for generating reactive intermediates. The last decade, extensive research has been carried out by Karst research group (Faber et al., 2014; Brauckmann et al., 2013; Baumann et al., 2010; Simon et al., 2016; Frensemeier et al., 2016) towards the electrochemical mimicry of various drugs. However, the proposed methodologies are focused on flow cells that are fabricated from expensive materials. Screen-printed electrodes (SPEs), are low cost disposable sensors with a three-electrode configuration (Working, Reference and Counter electrodes), providing in this way a miniaturized electrochemical cell. In literature, their capability on investigating drug formulations with their corresponding metabolites is limited (Radi et al., 2013; Kauffmann et al., 2011). Thus, further studies with different types of phase I reactions and multiple pathways are required to prove the efficient use of SPE in metabolism.

\footnotetext{
${ }^{*}$ Researcher, University of Hull, UK.
} 
Eugenol is an essential oil widely used by population as a food additive and local anesthetic (Kamatou et al., 2012; Martins et al., 2016). However, toxic events such as skin sensitization have been associated with eugenol metabolism (Scholes et al., 1994; Aljabr et al., 2017). The causal agent is the reactive intermediate eugenol phenoxyl radical, which leads to the generation of a second toxic substance known as eugenol quinone methide. Both metabolites can induce toxicity via macromolecule interaction (Thompson et al., 1989; Yamazoe and Mitsumori, 2016).

The metabolism of eugenol as shown in Figure 1, involves a series of metabolic pathways leading to polymerization, catalysis and conjugation. Initially, the transfer of a single electron and a proton leads to the formation of a highly reactive and unstable phenoxyl radical. Subsequently, the radical follows three metabolic routes 1) polymerization, 2) stabilization into a second reactive metabolite, the eugenol quinone methide which is either polymerized or detoxified via covalent conjugation with GSH and 3) catalysis in the presence of GSH, causing the regeneration of eugenol and the formation of glutathione disulfide (GSSG).

Figure 1. Eugenol Metabolism as Proposed by Thomson et al., 1989

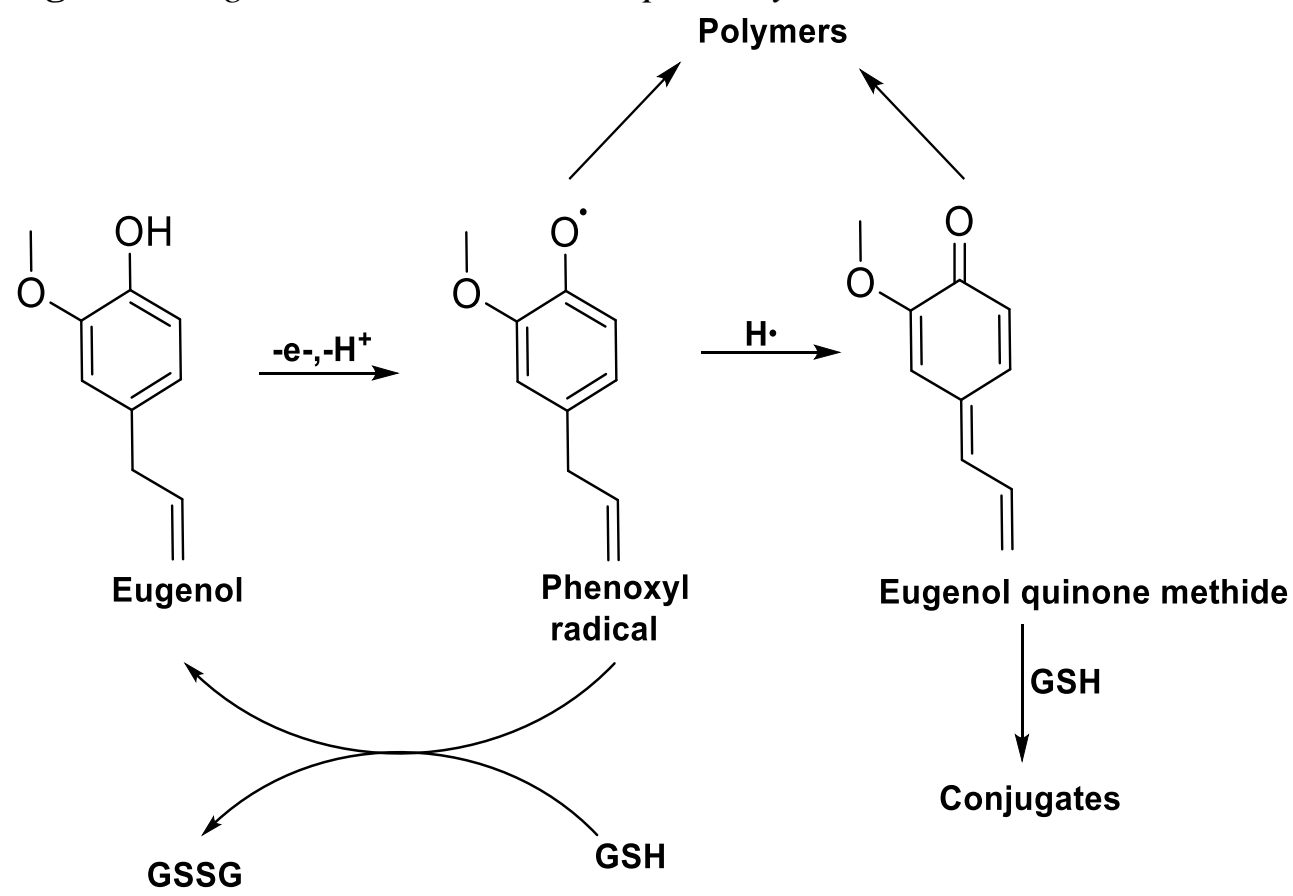

Herein, the mimicry of eugenol metabolism was investigated on SPEs and the electrogenerated metabolites were subsequently detected by ESI/MS. 


\section{Materials and Methods}

\section{Chemicals}

Eugenol was received by Alfa Aesar (UK) and L-Glutathione reduced was purchased from Sigma (UK). The aqueous buffers were prepared by ammonium acetate (Fisher, UK), adjusted to the appropriate $\mathrm{pH}$ using acetic acid (Fisher, UK), ammonium bicarbonate (Sigma, UK) and ammonium hydroxide (Sigma, UK).

\section{Sample Preparation}

Eugenol $\left(2.5 \times 10^{-4} \mathrm{M}\right)$ was initially dissolved in ethanol and then diluted in aqueous buffer solutions for a final concertation of $2.5 \times 10^{-5} \mathrm{M}$. The water was purified using an Elgastat prima 3 reverse osmosis unit (Elga Ltd., High Wycombe, UK). All solutions were degassed with pure nitrogen (99.9\%) for 15 min prior to electrochemical measurements.

\section{Screen-Printed Electrodes}

DRP-110 as shown in Figure 2, were purchased from DropSens (Spain) and used without any pretreatments. The sensor consisted of a carbon working electrode $(4 \mathrm{~mm})$, a silver reference electrode and a carbon counter electrode. Each time a new sensor was used to avoid memory effects.

Figure 2. Screen-Printed Electrode

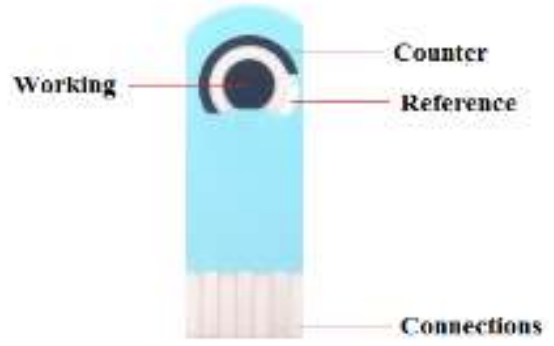

\section{Instrumentation}

The electrochemical measurements were recorded using an SP-50 potentiostat (Bio-Logic, France) controlled by EC-Lab V10.34 software (Bio-Logic, France). An edge connector interface from DropSens (DRP-DSC) was used to connect the sensor with potentiostat. The electrogenerated metabolites were detected using an LCQ classic ion trap mass spectrometer (Thermo Scientific, UK), coupled with an ESI and controlled by Xcalibur 2.0 software. 


\section{SPE / ESI-Mass Spectrometry}

Eugenol solution $(50 \mu \mathrm{L})$ was loaded into the SPE and electrolyzed at the applied potential. The electrogenerated intermediates were collected and detected offline by ESI/MS, in negative mode.

\section{Results and Discussion}

Electrochemical Behavior of Eugenol on SPE

Cyclic voltammograms of eugenol in $0.1 \mathrm{M}$ ammonium acetate $(\mathrm{pH}$ 6) were recorded at $0.1 \mathrm{Vs}^{-1}$, Figure 3 . An oxidation peak (A1) appeared during the forward scan at $0.21 \mathrm{~V}$ and two low magnitude reduction peaks at $0.120 \mathrm{~V}$ (B1) and $-0.120 \mathrm{~V}(\mathrm{C} 1)$ on reverse scan. A second cycle generated the corresponding anode peaks at $-0.150 \mathrm{~V}(\mathrm{~B} 2)$ and $-0.050 \mathrm{~V}(\mathrm{C} 2)$.

Figure 3. Voltametric Response of Eugenol on bare SPE A) First Cycle B) Second Cycle
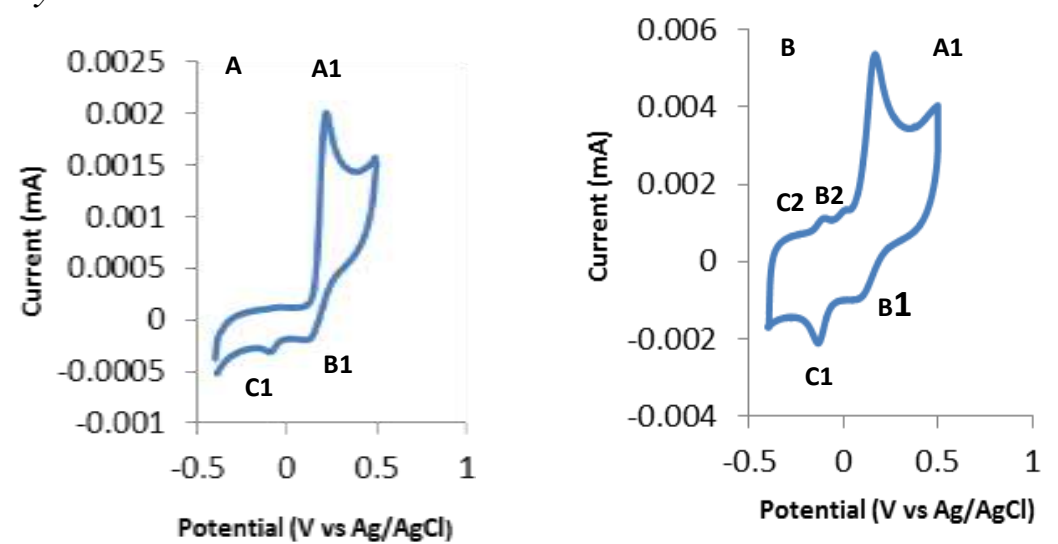

Eugenol as a monophenol was oxidized irreversibly into a phenoxyl radical (A1). During the second cycle reversible pairs were obtained that corresponded to the formation of electrodeposited products (Gil and Cout, 2013). The highly unstable nature of eugenol phenoxyl radical leaded to the formation of two resonance forms, which were hydrolyzed and reduced, generating in this way a catechol (B1) and a hydroquinone (C1), Figure 4. 
Figure 4. Reaction Mechanism of Phenoxyl Radical

A1<smiles></smiles>

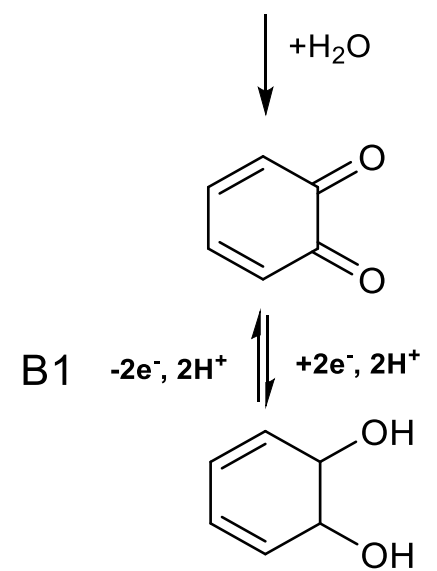<smiles>[O-]c1ccccc1</smiles><smiles>O=C1C=CCCC1</smiles><smiles>[Y6][CH-]O</smiles><smiles>O=C1C=CC(=O)C=C1</smiles>

C1

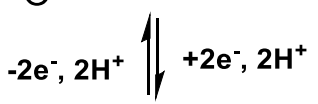

$\mathrm{HO}$<smiles>OC1C=CC(O)C=C1</smiles>

The formation of eugenol phenoxyl radical with its subsequent metabolites such as the eugenol quinone methide and the corresponding GSH products was the main focus of the particular study. Thus, the following electrochemical measurements were recorded on A1 peak (oxidation of eugenol), unless otherwise stated.

\section{Effect of $p H$}

The redox behavior of eugenol in different $\mathrm{pH}$ values from 2 to 12 was performed using cyclic voltammetry at $0.1 \mathrm{Vs}^{-1}$ scan rate and potential limits of $-0.4 \mathrm{~V}$ to $0.5 \mathrm{~V}$. A linear relationship $\left(\mathrm{R}^{2}=0.98\right)$ was obtained between the anode potential and $\mathrm{pH}$ figure 5, implying the participation of protons during the electron transfer process (Ullah et al., 2015; Ejaz et al., 2017).

Figure 5. Linear Relationship of Anode Potential with $\mathrm{pH}$

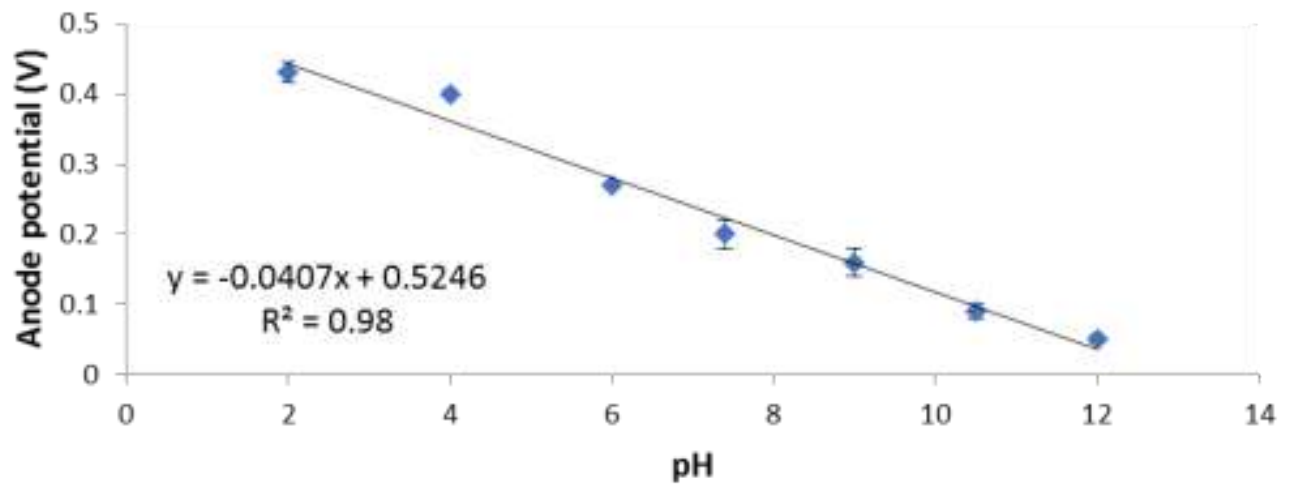




\section{Effect of Scan Rate}

The irreversibility of eugenol oxidation was investigated by differential pulse voltammetry (DPV), in various scan rates from $0.015 \mathrm{Vs}^{-1}$ to $0.155 \mathrm{Vs}^{-1}$. The measurements were performed in acidic media ( $\mathrm{pH} 6$ ) using $0.1 \mathrm{M}$ ammonium acetate, at the potential limits of $0 \mathrm{~V}$ to $0.5 \mathrm{~V}$. A plot of the anode current with square root (SQRT) of scan rate suggested a linear dependence $\left(\mathrm{R}^{2}\right.$ $=0.97$ ) Figure 6, illustrating clearly the slow electron kinetics (Ozksan et al., 2015).

Figure 6. Dependence of Anode Current with SQRT Scan Rate

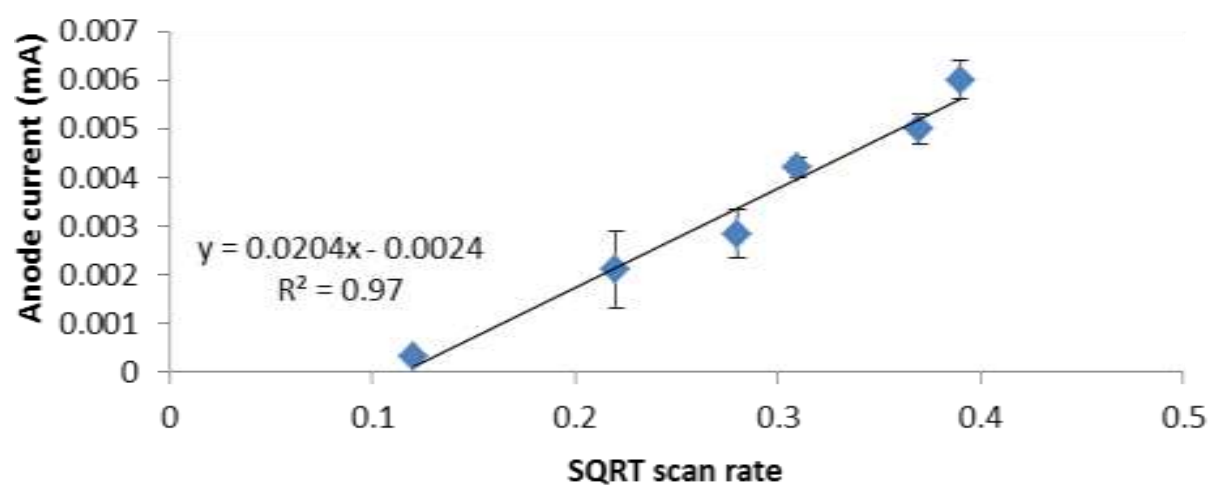

Variations in anode potential were also observed as a function of scan rate (Shah et al., 2015; Sheng et al., 2017), confirming further the irreversible nature of eugenol upon oxidation. As shown in Figure 7, anode potential shifted to more positive values with the increase of scan rate.

Figure 7. Variation of Anode Potential as a Function of Scan Rate

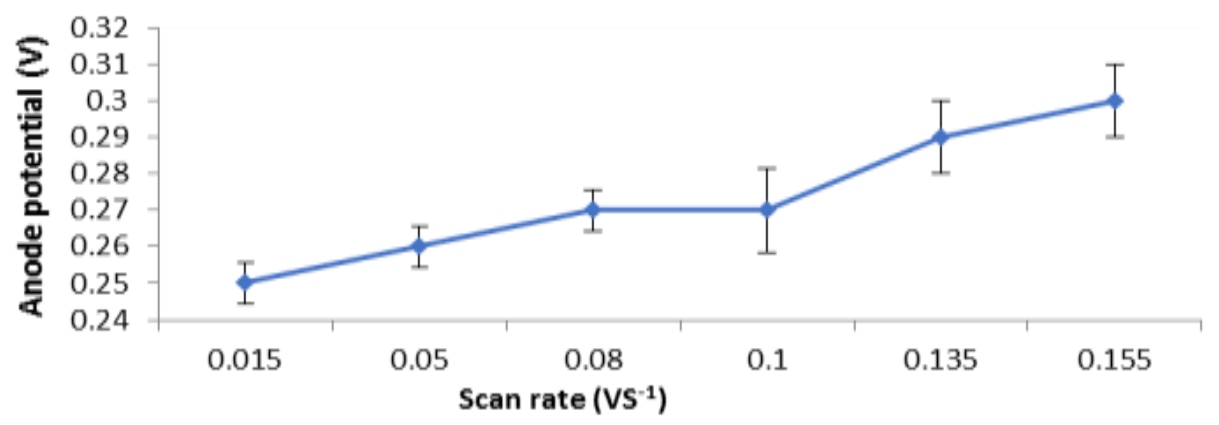

Furthermore, a plot of the logarithmic value of anode current with the logarithm of scan rate, illustrated a linear relationship. The obtained slope of 1.27 was close to 1 , implying the strong adsorption properties of eugenol on the SPE, Figure 8. Slopes below 0.5 imply a diffusion control process, whereas values near to 1 a total adsorption. A mixture of both adsorption and diffusion is obtained with slopes between 0.5 and 1 (Bagheri et al., 2012; Karadas-Bakirhan and Gumustas, 2016). 
Figure 8. A Plot of Log (Anode Current) Vs Log (Scan Rate)

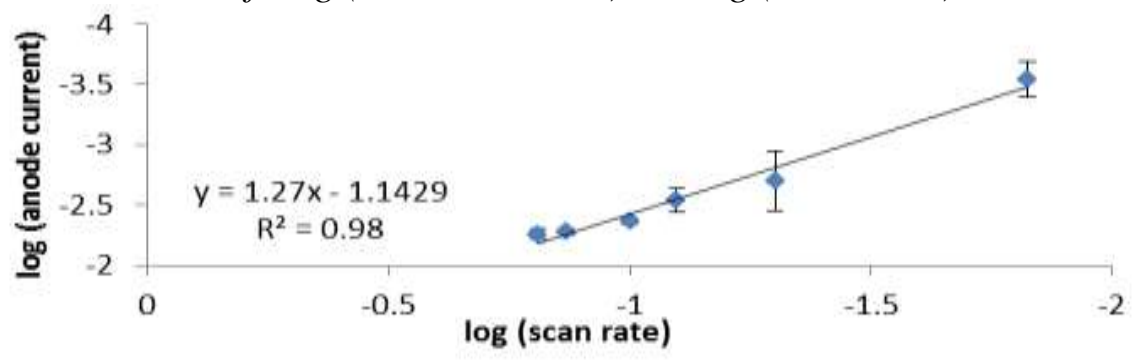

Effect of Eugenol Concertation

Figure 9. Cyclic Voltammograms in Various Eugenol Concentrations
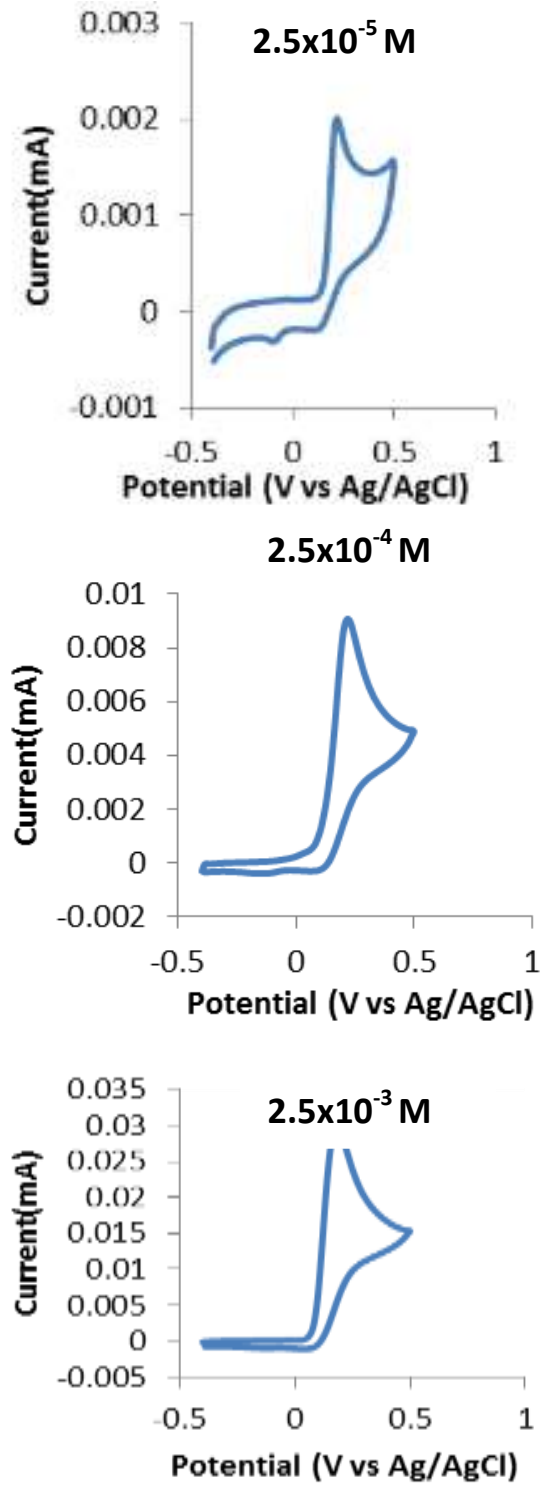
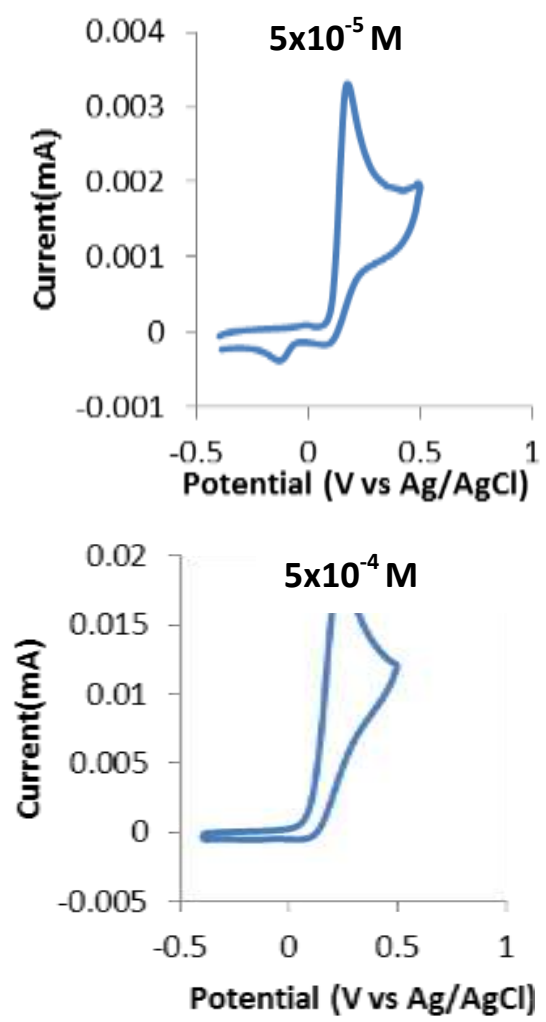

Eugenol in $0.1 \mathrm{M}$ of ammonium acetate $(\mathrm{pH} 6)$ was examined by cyclic voltammetry at various concentrations $(2.5 \times 10-5 \mathrm{M}$ to $2.5 \times 10-3 \mathrm{M})$. The 
potential limits were $\pm 0.5 \mathrm{~V}$ at $0.1 \mathrm{Vs}^{-1}$ scan rate. At lower concentrations of $2.5 \times 10^{-5} \mathrm{M}, 5 \times 10^{-5} \mathrm{M}$ and $2.5 \times 10^{-4} \mathrm{M}$, the corresponding cathode peaks were obtained, Figure 9. Whereas at higher concentrations of $5 \times 10^{-4} \mathrm{M}$ and $2.5 \times 10^{-3} \mathrm{M}$ only the anode potential was observed due to intermediate saturation. Any other peaks that might correspond to the formation of further metabolites as a function of concertation were not observed.

\section{Effect of GSH Concentration}

The voltammetric response of eugenol in various GSH concentrations from 0 $\mathrm{M}$ to $2.5 \times 10^{-4} \mathrm{M}$ was investigated by DPV. The potential limits were set from $0.1 \mathrm{~V}$ to $0.5 \mathrm{~V}$, at $0.1 \mathrm{Vs}^{-1}$ scan rate. As seen in Figure 10, the anode potential shifted to more positive values with the increase of GSH concentration, illustrating the formation of an electroactive metabolite. In addition, the anode current was also increased since both eugenol and electroactive intermediate were oxidized at the applied potential.

Figure 10. DPV in the Presence of Different GSH Concentrations
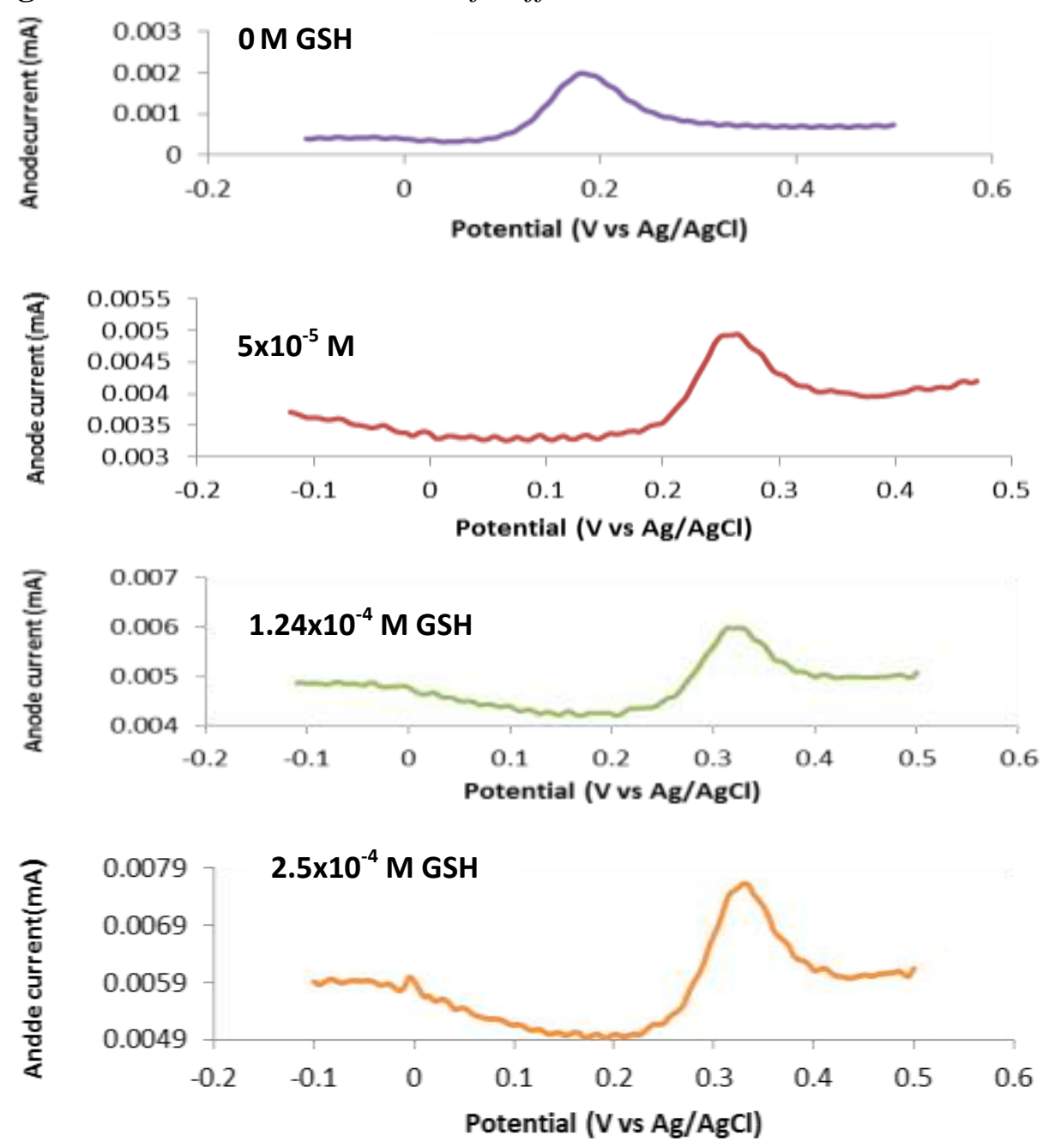


\section{Potential Optimization}

Eugenol in $0.1 \mathrm{M}$ ammonium acetate $(\mathrm{pH} 7.4)$ was electrolyzed for 0.5 min by control potential electrolysis (CPE), in the presence of $5 \times 10^{-5} \mathrm{M} \mathrm{GSH}$. The investigated potential range of $0.3 \mathrm{~V}-0.65 \mathrm{~V}$ was determined by DPV in the presence of $5 \times 10^{-5} \mathrm{M} \mathrm{GSH}$, Figure 10 and operated in a mass transport rate limit with increasing steps of $0.05 \mathrm{~V}$. As shown in Figure 11, the catalytic metabolite GSSG was obtained at all potentials; however, the corresponding GSH-adducts were not observed. At $0.45 \mathrm{~V} \mathrm{GSH}$ was depleted, as reflected on the obtained ion intensities and a dimer was formed, known as a bis-eugenol.

Figure 11. Potential Optimization of Eugenol Metabolism

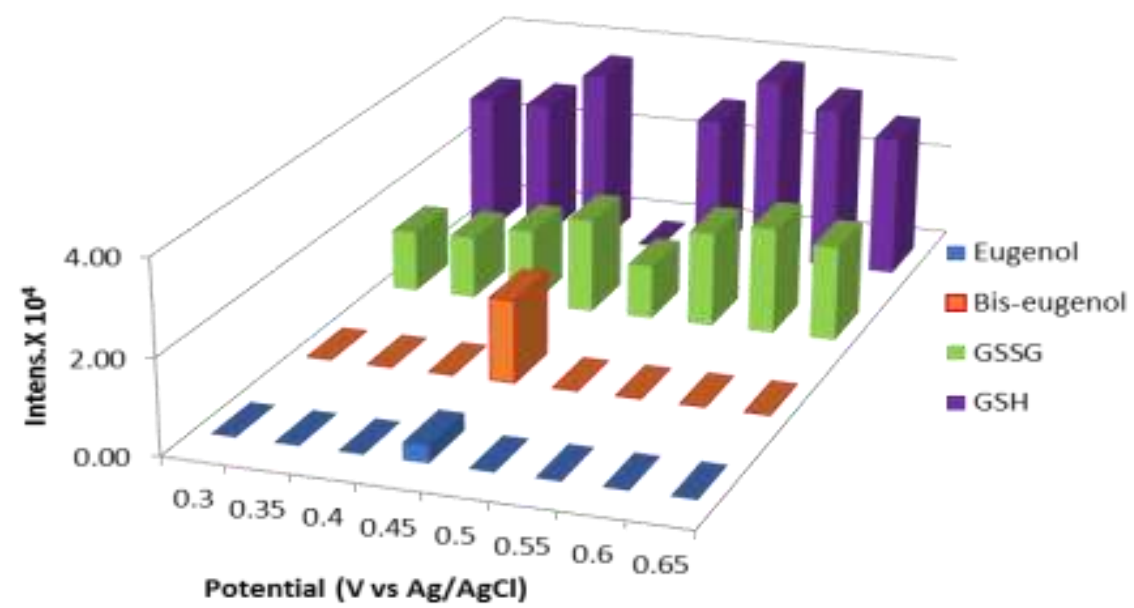

\section{Exhaustive Electrolysis}

Eugenol was electrolyzed for 30 minutes at $0.45 \mathrm{~V}$ (optimum potential), using the same conditions, as in potential optimization. The extended time of electrolysis caused the depletion of eugenol but the corresponding GSH-adducts were not obtained. The obtained mass spectrum at $0.45 \mathrm{~V}$ with the generated metabolites bis-eugenol $(\mathrm{m} / \mathrm{z}, 325.20)$ and GSSG $(\mathrm{m} / \mathrm{z}, 610.80)$ are shown in Figure 12. The electrochemical method was in a good agreement with the in vitro findings, as proposed by Thomson et al, suggesting the mimicry of peroxidase rather than CYP-450. A strong indication was the dimer formation, which was seen exclusively in peroxidase metabolism. 
Figure 12. Obtained Mass Spectrum of Eugenol Metabolism at $0.45 \mathrm{~V}$

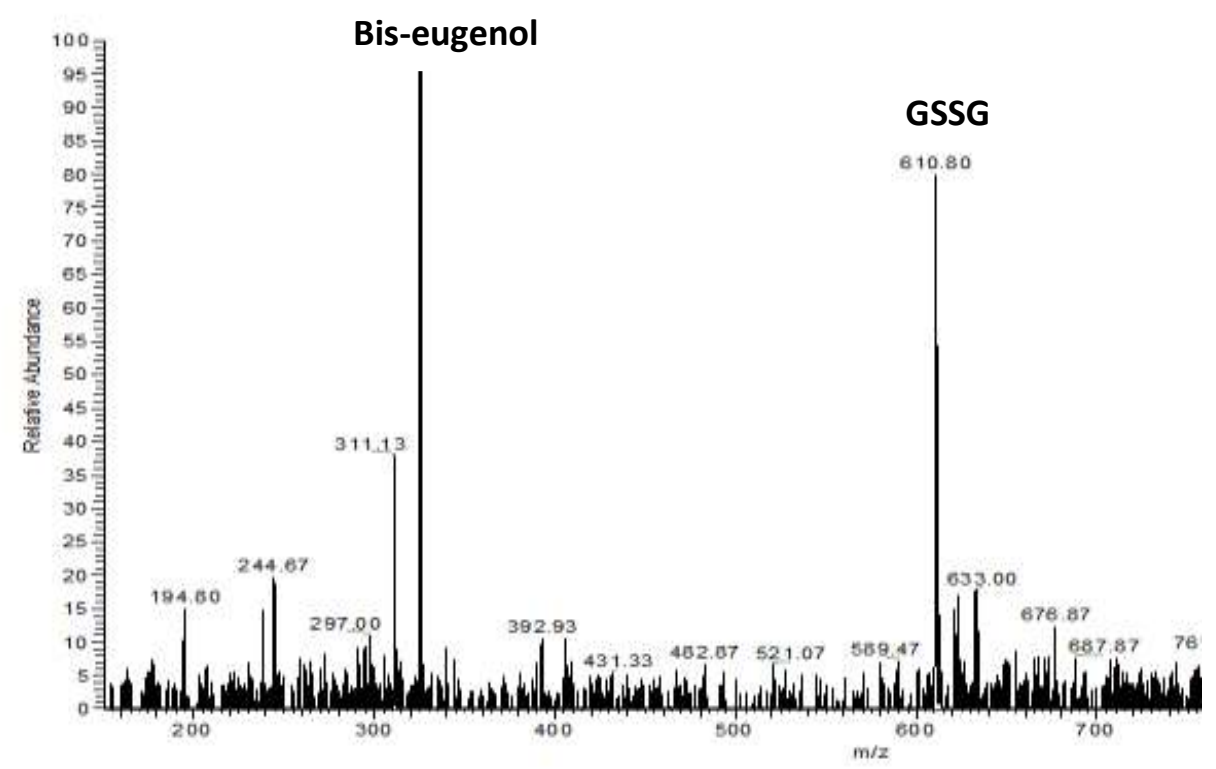

\section{Proposed Reaction Mechanism}

The proposed reaction mechanism is shown in Figure 13. Eugenol was oxidized electrochemically via a single electron and a proton to the corresponding phenoxyl radical. Subsequently, two metabolic pathways were followed 1) polymerization leading to bis-eugenol and 2) catalysis causing the regeneration of parent compound and GGSG formation. However, the GSH-adducts and as a consequence the corresponding eugenol quinone methide were not formed due to phenoxyl radical depletion. A similar behavior was seen in the in vitro methodology (Thomson et al., 1989), leading to low yields of GSH-adducts.

Electrochemical studies of eugenol (Melles et al., 2012) in conventional flow cell with a boron doped diamond generated metabolites that corresponded to CYP-450 enzyme. Thus, as concluded different electrodes and geometries can mimic different types of phase I enzymes, providing in this way a complete metabolic profiling.

Bis-eugenol as an electroactive compound with two phenol groups is capable to generate quinones upon oxidation. Thus, the obtained shifts in potentials during DPV Figure 10, resulted possibly from the dehydrogenation of bis-eugenol and not due to GSH-adduct oxidation. 
Figure 13. Proposed Reaction Mechanism for Eugenol Metabolism at $0.45 \mathrm{~V}$<smiles>CCCCCc1ccc(O)c(OC)c1</smiles><smiles>[3H][3H]</smiles><smiles></smiles><smiles>C=CCc1cc(CC=C)c(O)c(-c2cc(CC=C)cc(OC)c2O)c1</smiles>

Bis- eugenol

\section{Conclusions}

The metabolism of eugenol was mimicked successfully on a bare SPE. Both phase I and phase II metabolites such as eugenol phenoxyl radical, bis- eugenol and GSSG were generated inexpensively in $30 \mathrm{~min}$. The disposable nature of the SPEs provided a simple approach without any tedious cleaning methods or pretreatments. The proposed methodology has the potential to be used during the early stages of drug metabolism and reduce the in vitro and in vivo methodologies. 


\section{References}

Aljabr, A.M., Hussain, A., Rizwan-Ul-Haq, M and Al-Ayedh, H. 2017. Toxicity of plant secondary metabolites modulating detoxification genes expression for natural red palm weevil pesticide development. Molecules, 22(1): 169-180.

Andrade, E.L, Bento, A.F., Cavalli, J., Oliveira, S.K., Schwanke, R.C., Siqueira, J.M., Freitas, C.S., Marcon, R., Calixto, J.B. 2016. Non-clinical studies in the process of new drug development - part II: good laboratory practise, metabolism, pharmacokinetics, safety and dose translation to clinical studies. Brazilian journal of medical and biological research, 49 (12): 1-19.

Bagheri, A. and Hosseini, H. 2012. Electrochemistry of raloxifene on glassy carbon electrode and its determination in pharmaceutical formulations and human plasma. Bioelectrochemistry, 88: 164-170.

Baumann, A. and Karst, U. 2010. Online electrochemistry/mass spectrometry in drug metabolism studies: principles and applications. Expert Opinion on Drug Metabolism \& Toxicology, 6(6): 715-731.

Brauckmann, C., Faber, H., Lanvers-Kaminsky, C., Sperling, M. and Karst, U. 2013. Influence of cimetidine and its metabolites on Cisplatin-investigation of adduct formation by means of electrochemistry/liquid chromatography/electrospray mass spectrometry. Journal of Chromatography A, 1279: 49-57.

Chadwick, J. \& Shaw, C. I. 2002. Principles of environmental toxicology. Ed.1 Taylor and Francis, USA, 130.

Ejaz, A., Joy, Y and Jean, S. 2017. Fabrication of 1,4-bis(aminomethyl)benzene and cobalt hydoroxide at graphene oxide for selective detection of dopamine in the presence of ascorbic acid and serotonin. Sensors and actuators B: chemical, 240: 207-307.

Faber, H., Vogel, M. and Karst, U. 2014. Electrochemistry/mass spectrometry as a tool in metabolism studies-a review. Analytica Chimica Acta, 834: 9-21.

Frensemeier, M.L., Büter, L., Vogel, M. and Karst, U. 2016. Investigation of the oxidative transformation of roxarsone by electrochemistry coupled to hydrophylic interaction liquid chromatography/mass spectrometry. Journal of analytical atomic spectrometry, 32: 153-161.

Gil, E.S. and Cout, R.O. 2013. Flavonoid electrochemistry: a review on the electroanalytical applications. Brazilian journal of pharmacognosy, 23(3): 542-558.

Gul, T., Bischoff, R., Permentier, H.P. 2017. Mechanism of aromatic hydroxylation of lidocaine at a Pt electrode under acidic conditions. Electrochemical ACTA, 224: 636-641.

Kamatou, G.P., Vermaak, I. and Viljoen, A.M. 2012. Eugenol-From the Remote Maluku Islands to the International Market Place: A review of a Remarkable and Versatile Molecule. Molecules, 17: 6953-6981.

Karadas-Bakirhan, N., Gumustas, M., Uslu, B., Ozkan, S.A. 2016. Simultaneous determination of amlodipine besylate and rosuvastatin calcium in binary mixtures by voltametric and chromatographic techniques. International journal of ionics, 22(2): 277-288.

Kauffmann, J.M.,Van Antwerpen, P., Sarakbi, A., Feier, B., Tarik, S. and Aydogmus, Z. 2011. Electroanalysis, 23(11): 2643-2650.

Laffon, B., Bertolez-Fernandez, N., Costa, C., Pasaro, E., Valdiglesias, V. 2017. Comparative study of human neuronal and glial cell sensitivity for in vitro sensitivity neurogenotoxocity testing. Food and chemical toxicology, 102: 120-128.

Lohmann,W., Baumann A. and Karst, U. 2010. Electrochemistry and LC-MS for 
Metabolite Generation and Identification: Tools, Technologies and Trends. $L c G c$ Europe, 23(1): 1-7.

Martins, M.R., Farias, D.M., Nedel, F., De Pereira, M.P.C., Lencina, C and Lund, G.R. 2016. Antimicrobial and cytotoxic evaluation of eugenol derivatives. Medicinal chemistry research, 25(10): 2360-2367.

Melles, D., Vielhaber, T., Baumann, A., Zazzeroni, R and Karst, U. 2012. In chemico evaluation of skin metabolism: Investigation of eugenol and isoeugenol by electrochemistry coupled to mass spectrometry. Journal of chromatography B, 5: 106-112.

Ozksan, S.A., Kauffman, J. and M., Zuman, P. 2015. Electrolysis in biomedical and pharmaceutical sciences. Ed.1 Springer, Germany, 52.

Plumb, R. S., Stumpf, C. L., Granger, J. H., Castro-Perez, J., Haselden, J. N. and Dear, G. J. 2003. Use of liquid chromatography/time-of-flight mass spectrometry and multivariate statistical analysis shows promise for the detection of drug metabolites in biological fluids. Rapid Communications in Mass Spectrometry, 17(23): 26322638 .

Radi, A. E., Khafagy, A., El-shobagy, A and El-mezeyen, H. 2013. Anodic Voltammetric determination of gemifloxacin using screen-printed carbon electrode. Journal of pharmaceutical analysis, 3(2): 132-136.

Scholes, E.W., Pendlington, R.U., Sharma, R.K \& Basketter, D.A. 1994. Skin metabolism on contact allergens. Toxicology In Vitro, 8(4), 551-553.

Shah, A.H., Zaid, W., Ali Rana, U., Hussain, H., Ashiq, M.N., Qureshi, R and Badshah, A. 2015. pH Dependent Electrochemical Characterization, Computational Studies and Evaluation of Thermodynamic, Kinetic and Analytical Parameters of Two Phenazines. Journal of the electrochemical society, 162 (3): 115-123.

Sheng, K., Wang, L., Li, H., Zou, L and Ye, B. 2017. Green synthesized Co nanoparticles doped amino-graphene modified electrode and its application towards determination of baicalin. Talanta, 164: 249-256.

Simon, H., Hoffmann, G., Humph, Karst, U. 2016. Electrochemical simulation of metabolic reactions of secondary fungal metabolites alternariol and alternariol methyl ether. Analytical and bioanalytical chemistry, 408(10): 2471-2483.

Thompson, D., Norbeck, K., Olsson, L. I, Constantin-Teodosiu, D.,Vanderzee, J. and Moldeus, P. 1989. Peroxidase-catalyse oxidation of Eugenol: Formation of a cytotoxic metabolites (s). Journal of Biological Chemistry. 264(2):1016-1021.

Ullah, U., Rauf, A., Rana, U.M.J., Qureshi, A., Ashiq, R., Hussain, M. N., Kraatz, H., Badshah, H.B, A., and Shah. A. 2015. pH Dependent Electrochemistry of Anthracenediones at a Glassy Carbon Electrode. Journal of the Electrochemical Society, 162 (3): H157-H163.

Yamazoe, Y. and Mitsumori, K. 2016. Assessment of nongenotoxic mechanisms in carcinogenicity test of chemicals; quinone, quinone imine and quinone methides as examples. In Thresholds of genotoxic carcinogens: From mechanism to regulation. Nohmi,T and Fukushima, S. Ed 1 Elsevier, UK, 175-177. 
